\title{
Tamanho de estacas e uso de ácido indol-butírico ou preparado homeopático de Arnica montana na propagação de falsa-érica ${ }^{(1)}$
}

\author{
DARCIELI APARECIDA CASSOL (2), MARCELO DOTTO(2), \\ KELLI PIROLA ${ }^{(2)^{*}}$, AMÉRICO WAGNER JÚNIOR ${ }^{(3)}$
}

\begin{abstract}
RESUMO
O mercado de flores e plantas ornamentais está em crescimento, sendo que, a falsa-érica (Cuphea gracilis) é planta com diversos usos no paisagismo, adaptando-se a meia sombra ou a pleno sol podendo ser utilizada para forrações ou em combinações cromáticas com outras plantas. Usualmente, a falsa-érica é propagada por sementes ou por estacas. O objetivo foi avaliar o tamanho de estacas e a concentração de AIB (ácido indol-butírico) e preparado homeopático a base de Arnica montana no enraizamento de estacas de falsa-érica. A coleta de estacas foi realizada em plantas matrizes cultivadas em jardins abertos a pleno sol no município de Verê-PR nos tamanhos padronizados de 6 e 12 $\mathrm{cm}$ de comprimento, sendo as mesmas tratadas com AIB, nas concentrações de $0 ; 1.000$ e $2.000 \mathrm{mg} \mathrm{L}^{-1}$ além do preparado homeopático $A$. montana $12 \mathrm{CH}$. O experimento foi instalado em delineamento inteiramente casualizado, em fatorial $2 \times 4$ [comprimento da estaca $\mathrm{x}$ tratamento estimulante], com 4 repetições de 10 estacas por parcela. Após 45 dias, foram avaliados percentagem de estacas enraizadas e mortas, comprimento de raízes $(\mathrm{cm})$, número de brotos e número de folhas. As concentrações de AIB, bem como a aplicação de homeopatia estimularam os nos processos de enraizamento adventício desta espécie.
\end{abstract}

Palavras-chave: Cuphea gracilis, propagação vegetativa, planta ornamental.

\section{ABSTRACT \\ Behavior of piles and indolbutyric or homeopathic prepared acid Arnica montana spread of false-erica}

The market for flowers and ornamental plants is growing. Since the false-érica (Cuphea gracilis) is a plant with many uses in the landscape, adapting to partial shade or full sun can be used for ground covers or chromatic combinations with other plants. Usually, the false-erica is propagated by seeds or by cuttings. The objective of this study was to evaluate the size of stakes and the concentration of IBA (indole butyric acid) and prepared homeopathic base of Arnica montana in rooting false-erica stakes. The collection of cuttings was carried out in arrays plants grown in gardens in standard sizes 6 and $12 \mathrm{~cm}$ in length, and were treated with IBA at concentrations of $0 ; 1.000$ and 2.000 $\mathrm{mg} \mathrm{L}^{-1}$ in addition to the homeopathic preparation A. montana $12 \mathrm{CH}$. The experiment was conducted in a completely randomized design in a $2 \times 4$ factorial [length $\mathrm{x}$ stake stimulant treatment], with 4 replications of 10 cuttings per plot. After 45 days, they were evaluated percentage of rooted and dead cuttings, root length $(\mathrm{cm})$, number of shoots and number of leaves. The concentrations of AIB, and the application of homeopathy stimulated the adventitious rooting processes of this kind.

Keywords: Cuphea gracilis, vegetative propagation, ornamental plant.

\section{INTRODUÇÃO}

No Brasil, a floricultura mostrou plena expansão configurando-a em um dos mais promissores segmentos do agronegócio nacional, com a comercialização e distribuição de flores e plantas ornamentais regido principalmente por fornecedores e atacadistas presentes na CEAGESP-SP e a CEASA-Campinas sendo segmento promissor no país. Conforme dados do Instituto Brasileiro de Floricultura, responsável por gerar US $\$ 1,3$ bilhões por ano e, em torno de 3,7 empregos diretos por hectare
(JUNQUEIRA e PEETZ, 2008), o que demonstra possibilidades para novos locais. Este nicho de mercado caracteriza-se pela ampla concorrência, e por este motivo, é necessário qualidade, produtividade, padronização de mudas, embalagens e apresentação adequada do produto a fim de atingir boa aceitação, para tornar-se competitivo e agregando-se valor na venda (ARNALDI e PEROSA, 2007). Porém, o que se vê no mercado são espécies tradicionalmente comercializadas e algumas que entram como diferencial, buscando atrair consumidores ávidos por novidades.

\footnotetext{
DOI: http://dx.doi.org/10.14295/oh.v23i2.945

(1) Received in 25/08/2016 and acceted in 03/05/2017.

(2) Universidade Tecnológica Federal do Paraná, Campus Pato Branco, Pato Branco-PR, Brasil. *Autor correspondente: kelli_pirola1@hotmail.com

(3) Universidade Tecnológica Federal do Paraná, Câmpus Dois Vizinhos, Dois Vizinhos-PR, Brasil

Licensed by CC BY 4.0.
} 
A falsa-érica tem grande destaque pelas suas inúmeras flores minúsculas que tornam a planta muito chamativa, com diversos usos no paisagismo, adaptando-se a meia sombra ou a pleno sol, podendo ser utilizada para forrações e ainda em maciços nas combinações cromáticas com outras plantas, dada a suas flores lilases, pois mesmo que pequenas se destacam pela quantidade e beleza.

A falsa-érica pode propagar-se por sementes ou por estacas (LORENZI e SOUZA, 2008), porém o método assexuado permite a obtenção de plantas idênticas à mãe e em período de tempo reduzido se comparado ao método sexuado (DONADIO et al., 1992). Além destas vantagens pode-se destacar ainda a possibilidade de obtenção de grande número de estacas a partir de mesma planta matriz com fácil execução e baixo custo (FACHINELLO et al., 2005). Contudo, para isso é necessário o estabelecimento de protocolo eficiente.

Para maximizar, uniformizar e acelerar o enraizamento das estacas de algumas espécies a níveis satisfatórios é importante e necessário o uso de reguladores vegetais. Com isso, as auxinas são substâncias deste grupo que apresentam efeitos quanto ao estímulo para acelerar a formação de radicelas (FACHINELLO et al., 2005). O uso de AIB de forma exógena tem a finalidade de acelerar o processo de enraizamento e é comum utilizar várias concentrações desta auxina, variando-as de acordo com o tipo de estaca, espécie, época do ano, todavia existe uma faixa ideal para cada espécie (WENDLING e XAVIER, 2005). Por isso, é necessário que se defina qual faixa de concentração de AIB é mais indicada para falsa-érica.

No mercado, existe a disponibilidade de aquisição de auxinas sintéticas como ácido-indol-butírico, ácido naftaleno acético e ácido indol acético, o que nem sempre é facilmente acessível e ao adquiri-los aumentam o custo de produzir a muda. Neste sentido, poder-se-ia utilizar extratos/preparados vegetais que apresentem auxinas em sua composição. É conhecido empiricamente que o produto homeopático produzido a partir da Arnica montana, também possui efeito de estímulo ao enraizamento.

Para o alecrim, os tratamentos 3 e $6 \mathrm{CH}$ de $A$. montana aumentaram o comprimento da raiz, e $6 \mathrm{CH}$ aumentou a porcentagem e a qualidade do enraizamento. Em Lippia alba as altas diluições 3, 6 e $12 \mathrm{CH}$ aumentaram o número de ramos, o comprimento da raiz e a qualidade do enraizamento e, com $6 \mathrm{CH}$ aumentou-se a porcentagem de enraizamento (BONFIM et al., 2008).

Segundo Casali et al. (2006), A. montana $6 \mathrm{CH}$ aumentou a massa da parte aérea de mudas provenientes de estacas enraizadas de Ocimum gratissimum, além de aumentar o número de brotações e de enraizamento de estacas enraizadas de L. Alba. Desta maneira, faz-se necessária a pesquisa e a utilização da estaquia utilizando fitorregulador e a homeopatia como possibilidade de propagação da falsa-érica.

O objetivo deste trabalho foi avaliar o efeito do ácido indol-butírico e do preparado homeopático a base de Arnica montana na propagação de falsa-érica.

\section{MATERIAL E MÉTODOS}

O experimento foi realizado na Unidade de Ensino e Pesquisa - Viveiro Produção de Mudas da Universidade Tecnológica Federal do Paraná, Câmpus Dois Vizinhos, situada na região sudoeste do Paraná, altitude de 509 metros acima do nível do mar, o solo nitossolo vermelho distroférrico, (EMBRAPA, 2006). Quanto ao clima, segundo classificação de Köppen, é do tipo Cfa subtropical úmido mesotérmico e verão quente, sem estação seca definida, temperatura média do mês mais frio, inferior a 18 ${ }^{\circ} \mathrm{C}$ e o mês mais quente, acima de $22{ }^{\circ} \mathrm{C}$. Ocorrem geadas frequentemente, umidade relativa do ar varia em média de 64 a 74\% e precipitação pluviométrica entre 1.800 a 2.200 $\mathrm{mm}$ bem distribuída ao longo do ano (MAACK, 1981).

As estacas foram coletadas de plantas matrizes $C$. gracilis em propriedade rural do Verê, PR. Após a coleta as estacas foram acondicionadas em baldes com água, evitando-se a desidratação e oxidação das mesmas, sendo então, transportadas para universidade (distância de $35 \mathrm{~km}$ ). Foram retiradas as folhas das estacas, sendo posteriormente preparadas nos comprimentos de 6 e $12 \mathrm{~cm}$ de comprimento, cujo diâmetro era de aproximadamente $0,3 \mathrm{~cm}$.

Nas estacas foram realizadas duas lesões superficiais na parte basal, em lados opostos, retirando-se porção da casca de cerca de $0,5 \mathrm{~cm}$ de largura por $0,3 \mathrm{~cm}$ de extensão. As concentrações de AIB testadas foram de 0, 1.000 e $2.000 \mathrm{mg} \mathrm{L}^{-1}$, para preparo da solução de AIB, o mesmo foi dissolvido em hidróxido de potássio $\left(\mathrm{KOH}_{5} \mathrm{~N}\right)$ e álcool etílico absoluto, sendo posteriormente diluído em água destilada até a concentração desejada. e do preparado Homeopático a partir de $A$. montana de $12 \mathrm{CH}$ (Centesimal Hannemanniana). As aplicações destas soluções foram realizadas por imersão rápida ( 5 segundos) na base das estacas $(1,5 \mathrm{~cm})$. Na concentração de $0 \mathrm{mg} \mathrm{L}^{-1}$ utilizouse a imersão em água. O preparado homeopático a partir de A. montana de $12 \mathrm{CH}$ foi adquirido em farmácia de manipulação especializada, sendo que as estacas permaneceram em imersão por 5 segundos.

Posteriormente, as estacas foram enterradas verticalmente até $1 / 3$ de seu comprimento em bandejas plásticas retangulares $(19 \times 12 \times 6 \mathrm{~cm})$ com tampa articulada, a fim de manter a temperatura dentro da bandeja, contendo areia como substrato e mantidas em casa de vegetação, com tela de sombreamento de $50 \%$. As irrigações foram realizadas diariamente, observando-se antes das mesmas a umidade do substrato.

O delineamento experimental foi em blocos completamente casualizados num fatorial 2 x 4 [comprimento da estaca $\mathrm{x}$ tratamento estimulante], com 4 repetições, considerando-se o uso de 10 estacas por parcela.

Após 45 dias da implantação do experimento foram avaliados porcentagem de estacas enraizadas e mortas, comprimento de raízes $(\mathrm{cm})$, número de brotos e número de folhas. Os dados foram submetidos à análise de variância e a comparação de médias pelo teste de Tukey $(\alpha=0,05)$. 
De acordo com o teste de normalidade de Lilliefors, não foi necessária fazer a transformação dos dados. Para as análises foi utilizado o aplicativo computacional ASSISTAT (SILVA e AZEVEDO, 2009).

\section{RESULTADOS E DISCUSSÃO}

A interação, comprimento de estacas $x$ tratamento estimulante, mostrou-se significativa em todas as variáveis analisadas (Tabelas 1, 2, 3, 4 e 5).

Tabela 1. Estacas enraizadas (\%), de acordo com tratamento estimulante comprimento de estacas.

Table 1. Rooted cuttings (\%), according to the stimulating treatment length cutte.

\begin{tabular}{|c|c|c|}
\hline \multirow{2}{*}{ Concentração } & \multicolumn{2}{|c|}{ Tamanho de estacas (cm) } \\
\hline $0 \mathrm{mg} \mathrm{L}^{-1} \mathrm{AIB}$ & $\mathbf{6}$ & $\mathbf{1 2}$ \\
\hline $1.000 \mathrm{mg} \mathrm{L}^{-1} \mathrm{AIB}$ & $22,50 \mathrm{bB}^{*}$ & $100,00 \mathrm{aA}$ \\
\hline $2.000 \mathrm{mg} \mathrm{L}^{-1} \mathrm{AIB}$ & $77,50 \mathrm{aA}$ & $82,50 \mathrm{aA}$ \\
\hline A. montana $12 \mathrm{CH}$ & $100,00 \mathrm{aA}$ & $100,00 \mathrm{aA}$ \\
\hline $\mathbf{C V}(\mathbf{\%})$ & $97,50 \mathrm{aA}$ & $97,50 \mathrm{aA}$ \\
\hline
\end{tabular}

"Médias com letras diferentes, minúscula na mesma coluna e maiúsculas na mesma linha, diferem pelo teste de Tukey ( $\alpha=0,05)$.

Quanto a percentagem de estacas enraizadas obteve-se médias estatisticamente semelhantes entre as estacas de 6 e $12 \mathrm{~cm}$ quando se fez uso de AIB nas concentrações de 1.000 e $2.000 \mathrm{mg} \mathrm{L}^{-1}$, bem como para o tratamento com A. montana, cujos valores variaram entre 77,5 a $100 \%$. Por outro lado, no uso de $0 \mathrm{mg} \mathrm{L}^{-1}$, as estacas de $6 \mathrm{~cm}$ apresentaram médias inferiores em comparação aquelas de $12 \mathrm{~cm}$.

Estes resultados sugerem que as estacas de $12 \mathrm{~cm}$ apresentaram maior quantidade de reservas, importantes para divisão celular e posterior diferenciação celular, necessárias para ambos os processos de rizogênese e brotação, conforme verificado por Tofanelli et al. (2003) com porta-enxerto de pessegueiro Okinawa e descrito por Hartmann et al. (2011).

Tal fato pode ser observado na avaliação de estacas enraizadas dentro dos $12 \mathrm{~cm}$ de comprimento, pois as médias assemelham-se estatisticamente entre os tratamentos, fato que pode ter sido proporcionado pela quantidade de reservas presentes nestas, fato não demonstrado pelas de $6 \mathrm{~cm}$.

Dentro destas estacas de $6 \mathrm{~cm}$ observou-se as maiores médias naquelas tratadas com AIB em ambas concentrações (1.000 e $2.000 \mathrm{mg} \mathrm{L}^{-1}$ ) e com A. montana, demonstrando que a aplicação de tal produto homeopático influenciou também favoravelmente ao enraizamento.

Bonfim et al. (2008), avaliando a influência do preparado homeopático de $A$. montana na formação de raízes de alecrim (Rosmarinus officinalis L.) e erva-cidreira (Lippia alba) nas diluições $3 \mathrm{CH}, 6 \mathrm{CH}$ e $12 \mathrm{CH}$, verificaram que estes favoreceram a formação de raízes, acentuando a semelhança entre $A$. montana e o quadro induzido pelo processo fisiológico de enraizamento de estacas.

O crescimento das raízes é muito importante, pois são responsáveis pela absorção de água e nutrientes utilizados em todos os processos de crescimento das plantas (TAIZ e ZEIGER, 2013).

Por isso, o uso do preparado homeopático de arnica torna-se viável aos produtores de mudas, uma vez que demonstrou ser eficiente como promotor de enraizamento de estacas de falsa-érica, diminuindo assim, os custos na produção de mudas, já que os hormônios de enraizamento normalmente são de alto custo. Alves et al. (2015), também verificou esta eficiência do preparado homeopático de $A$. montana $6 \mathrm{CH}$ no enraizamento de estacas de espinheira-santa (Maytenus aquifolium), sendo prática viável na propagação vegetativa destas estacas caulinares. Casali et al. (2012), também confirma o uso deste preparado em Rosmarinus officinalis L. e Lippia alba, confirmando assim o seu uso como preparado homeopático em plantas que sofreram de algum tipo de trauma e/ou estresse, como, a estaquia.

Além do enraizamento, acredita-se que esta quantidade de reservas tenha influenciado sobre a percentagem de estacas mortas, pois naquelas com $0 \mathrm{mg} \mathrm{L}^{-1}$ de AIB, as de menor comprimento apresentaram maior mortalidade, fato não obtido nos demais tratamentos (1.000 e 2.000 $\mathrm{mg} \mathrm{L}^{-1}$ e A. montana) cujas médias assemelharam-se estatisticamente entre si (Tabela 2). 
Tabela 2. Estacas mortas (\%), de acordo com o tratamento estimulante e comprimento de estacas.

Table 2. Mortality (\%), according to the stimulating treatment and length cutte.

\begin{tabular}{|c|c|c|}
\hline \multirow{2}{*}{ Concentração } & \multicolumn{2}{|c|}{ Tamanho de estacas (cm) } \\
\hline $0 \mathrm{mg} \mathrm{L}^{-1} \mathrm{AIB}$ & $\mathbf{6}$ & $\mathbf{1 2}$ \\
\hline $1.000 \mathrm{mg} \mathrm{L}^{-1} \mathrm{AIB}$ & $77,50 \mathrm{aA}^{*}$ & $0,02 \mathrm{aB}$ \\
\hline $2.000 \mathrm{mg} \mathrm{L}^{-1} \mathrm{AIB}$ & $22,50 \mathrm{bA}$ & $17,50 \mathrm{aA}$ \\
\hline A. montana $12 \mathrm{CH}$ & $0,01 \mathrm{bA}$ & $0,02 \mathrm{aA}$ \\
\hline CV (\%) & $2,50 \mathrm{bA}$ & $2,51 \mathrm{aA}$ \\
\hline
\end{tabular}

*Médias com letras diferentes, minúscula na mesma coluna e maiúsculas na mesma linha, diferem pelo teste de Tukey $(\alpha=0,05)$.

Nas estacas de $12 \mathrm{~cm}$, os tratamentos não diferiram suas médias estatisticamente para mortalidade, fato não repetido nas de $6 \mathrm{~cm}$, cujas maiores médias foram com os tratamentos com AIB nas concentrações de 1.000 e $2.000 \mathrm{mg} \mathrm{L}^{-1}$ e com $A$. montana (Tabela 2).

Isso comprova que o tratamento homeopático com $A$. montana não apresentou toxicidade nas estacas, cujas médias de mortalidade ficaram com 2,5\% em ambos comprimentos de estacas (Tabela 2).

Para o comprimento de radicelas, nas estacas de $6 \mathrm{~cm}$ as maiores médias foram obtidas com aquelas tratadas com 1.000 e $2.000 \mathrm{mg} \mathrm{L}^{-1}$ de AIB e com A. montana, comprovando o efeito favorável destes tratamentos. Naquelas de $12 \mathrm{~cm}$, as maiores médias para essa variável foram conseguidas com $0 \mathrm{e}$ $2.000 \mathrm{mg} \mathrm{L}^{-1}$ de AIB e, com A. montana (Tabela 3).

Estacas com comprimento de radicelas maiores tendem a favorecer para o maior crescimento de mudas, o que é desejável para ambos os casos, viveirista e consumidor. Nas estacas tratadas com 1.000 e $2.000 \mathrm{mg} \mathrm{L}^{-1}$ de AIB e, com A. montana as médias pra o comprimento de radicelas não diferenciaram entre si para ambos comprimentos testados, sendo diferente daquelas em que se fez uso de $0 \mathrm{mg} \mathrm{L}^{-1}$, no qual mais uma vez mostrou superioridade com aquelas de 12 cm (Tabela 3).

Tabela 3. Comprimento de radicelas $(\mathrm{cm})$, de acordo com o tratamento estimulante e comprimento de estacas. Table 3. Root length (cm), according to the stimulating treatment and length cutte.

\begin{tabular}{|c|c|c|}
\hline Concentração & \multicolumn{2}{|c|}{ Tamanho de estacas (cm) } \\
\hline $0 \mathrm{mg} \mathrm{L}^{-1} \mathrm{AIB}$ & 6 & 12 \\
\hline $1.000 \mathrm{mg} \mathrm{L}^{-1} \mathrm{AIB}$ & $2,77 \mathrm{bB}^{*}$ & $4,83 \mathrm{aA}$ \\
\hline $2.000 \mathrm{mg} \mathrm{L}^{-1} \mathrm{AIB}$ & $6,13 \mathrm{aA}$ & $7,35 \mathrm{abA}$ \\
\hline A. montana $12 \mathrm{CH}$ & $6,77 \mathrm{aA}$ & $7,28 \mathrm{abA}$ \\
\hline CV (\%) & $3,79 \mathrm{abA}$ & $\mathbf{2 8 , 9 1}$ \\
\hline
\end{tabular}

"Médias com letras diferentes, minúscula na mesma coluna e maiúsculas na mesma linha, diferem pelo teste de Tukey $(\alpha=0,05)$.

Já ao analisar o número de brotações por estaca, naquelas de $6 \mathrm{~cm}$ as médias assemelharam-se estatisticamente entre si nos tratamentos testados, fato que não foi seguido pelas de $12 \mathrm{~cm}$, uma vez que aquelas tratadas com $A$. montana apresentaram a maior média, fato que é desejável e vantajoso, pois uma muda com maior número de brotações apresentase com padrão mais avançado de pré-formação, o que pode agregar valor no momento da comercialização. Além disso, pode-se observar o efeito favorável deste tratamento homeopático na diferenciação e consequente brotação de maior número de gemas, influenciando no processo de formação como um todo, parte aérea e sistema radicular.

Nos tratamentos de $0,1.000$ e $2.000 \mathrm{mg} \mathrm{L}^{-1}$ de AIB as médias obtidas entre ambos comprimentos não diferiram estatisticamente entre si para o número de brotações. Por outro lado, com A. montana, as de $12 \mathrm{~cm}$ apresentaram maior média em relação as de $6 \mathrm{~cm}$ (Tabela 4). Isso reforça o efeito positivo da $A$. montana sobre as gemas, por acreditar-se que nas de maior comprimento o número de gemas seja superior em relação as de $6 \mathrm{~cm}$ e com isso tal tratamento pode fazer com que tal diferença fosse vantajosa para tais estacas de $12 \mathrm{~cm}$, fato não conseguido nos demais tratamentos. Em partes, isso também favoreceu sobre o número de folhas, uma vez que ao tratar as estacas de 12 $\mathrm{cm} \operatorname{com} A$. montana, estas foram superiores as de $6 \mathrm{~cm}$. Tal comportamento não se repetiu nos demais tratamentos, já que as médias assemelharam-se estatisticamente entre os comprimentos testados (Tabela 5). A mesma semelhança estatística entre as médias foi obtido nas estacas de $6 \mathrm{~cm}$ comparando-se os tratamentos. 
Tabela 4. Número de brotação, de acordo com o tratamento estimulante e comprimento de estacas.

Table 4. Number of shotting, according to the stimulating treatment and length cutte.

\begin{tabular}{|c|c|c|}
\hline Concentração & \multicolumn{2}{|c|}{ Tamanho de estacas (cm) } \\
\hline $0 \mathrm{mg} \mathrm{L}^{-1} \mathrm{AIB}$ & 6 & 12 \\
\hline $1.000 \mathrm{mg} \mathrm{L}^{-1} \mathrm{AIB}$ & $1,87 \mathrm{aA}^{*}$ & $1,62 \mathrm{bA}$ \\
\hline $2.000 \mathrm{mg} \mathrm{L}^{-1} \mathrm{AIB}$ & $1,31 \mathrm{aA}$ & $1,80 \mathrm{bA}$ \\
\hline A. montana $12 \mathrm{CH}$ & $2,05 \mathrm{aA}$ & $4,23 \mathrm{aA}$ \\
\hline CV $(\%)$ & $1,12 \mathrm{aB}$ & $\mathbf{3 5 , 4 2}$ \\
\hline
\end{tabular}

"Médias com letras diferentes, minúscula na mesma coluna e maiúsculas na mesma linha, diferem pelo teste de Tukey $(\alpha=0,05)$.

Tabela 5. Número de folhas, de acordo com o tratamento estimulante e comprimento de estacas.

Table 5. Number of leaves, according to the stimulating treatment and length cutte.

\begin{tabular}{|c|c|c|}
\hline Concentração & \multicolumn{2}{|c|}{ Tamanho de estacas (cm) } \\
\hline $0 \mathrm{mg} \mathrm{L}^{-1} \mathrm{AIB}$ & 6 & 12 \\
\hline $1.000 \mathrm{mg} \mathrm{L}^{-1} \mathrm{AIB}$ & $7,87 \mathrm{aA}^{*}$ & $7,82 \mathrm{bA}$ \\
\hline $2.000 \mathrm{mg} \mathrm{L}^{-1} \mathrm{AIB}$ & $5,15 \mathrm{aA}$ & $6,62 \mathrm{bA}$ \\
\hline A. montana $12 \mathrm{CH}$ & $6,95 \mathrm{aA}$ & $9,25 \mathrm{abA}$ \\
\hline CV (\%) & $3,20 \mathrm{aB}$ & $13,80 \mathrm{aA}$ \\
\hline
\end{tabular}

*Médias com letras diferentes, minúscula na mesma coluna e maiúsculas na mesma linha, diferem pelo teste de Tukey $(\alpha=0,05)$.

Nas estacas de $12 \mathrm{~cm}$, as maiores médias para o número de folhas foram obtidas com $2.000 \mathrm{mg} \mathrm{L}^{-1}$ de AIB e A. montana, demonstrando que talvez tal tratamento homeopático possua em sua composição grande quantidade de auxina.

As folhas nas plantas são muito importantes, pois que elas são responsáveis pela produção fotossintética e para translocação de água e solutos, que serão utilizados para o desenvolvimento das plantas (TAIZ e ZEIGER, 2013).

\section{CONCLUSÃO}

Para a propagação de falsa-érica, recomenda-se o uso de estacas com $12 \mathrm{~cm}$, tratadas com o preparado homeopáticos a base de Arnica montana.

\section{REFERÊNCIAS}

ALVES, L.F.; BONFIM, F.P.G.; OLIVEIRA, S.G. Preparados homeopáticos no enraizamento de estacas caulinares de espinheira-santa. Cadernos de Agroecologia, v. 10, n. $3,2015$.

ARNALDI, C.R.; PEROSA, J.M.Y. Perdas físicas, energéticas e econômicas em dois sistemas de comercialização de rosas no Estado de São Paulo. Revista Energia na Agricultura, v. 22, n. 3, p. 1-14, 2007.
BONFIM, F.P.G.; MARTINS, E.R.; DORES, R.G.R.; BARBOSA, C.K.R.; CASALI, V.W.D.; HONÓRIO, I.C.G. Use of homeopathic Arnica montana for the issuance of roots of Rosmarinus officinalis L. and Lippia alba (Mill) N.E.Br. Guaratinguetá, International Journal of High Dilution Research, v. 23, n. 7, p. 113-117, 2008.

CASALI V.W.D., CASTRO D.M.; ANDRADE F. Homeopatia: bases e princípios. Viçosa: Universidade Federal de Viçosa/DFT. 2006. 149p.

DONADIO, L.C.; MARTINS, A.B.G.; VALENTE, J.P. Fruticultura tropical. Jaboticabal: FUNEP, 1992. 268p.

EMBRAPA. EMPRESA BRASILEIRA DE PESQUISA AGROPECUÁRIA. Sistema brasileiro de classificação de solos. Embrapa: Rio de Janeiro, 2006. 306p.

FACHINELLO, J.C.; HOFFMANN, A.; NACHTIGAL, J.C. Propagação de plantas frutíferas. Brasília, Embrapa Informação Tecnológica, 2005. 221p.

HARTMANN, H.T.; KESTER, D.E.; DAVIES JR, F.T.; GENEVE, R.L. Plant propagat ion: principles and practices. 8 th ed. New Jersey: Prentice Hall, 2011. 915p. 
JUNQUEIRA, A.H.; PEETZ, D.S. Mercado interno para os produtos da floricultura brasileira: características, tendências e importância socioeconômica recente. Revista Brasileira de Horticultura Ornamental, v. 14, n. 1, p. 37- 52, 2008.

LORENZI, H.; SOUZA, H.M. Plantas ornamentais no Brasil: arbustivas, hebáceas e trepadeiras. 4 ed. Nova Odessa: Instituto Plantarum. 2008. 1088p.

MAACK, R. Geografia física do Estado do Paraná. Rio de Janeiro: J. Olympio, 1981.
TAIZ, L.; ZEIGER, E. Fisiologia vegetal. 5. ed. Porto Alegre: Artmed, 2013. 954p.

TOFANELLI, M.B.D.; RODRIGUES, J.D.; ONO, E.O. Enraizamento de estacas lenhosas de pessegueiro cv. Okinawa em diferentes diâmetros de ramos, substratos e recipientes. Ciência Rural, v. 33, n. 03, p. 437- 442, 2003.

WENDLING, I.; XAVIER, A. Influência do ácido indolbutírico e da mini estaquia seriada no enraizamento e vigor de mini estacas de clones de Eucalyptus grandis. Revista Árvore, v. 29, p. 921-930, 2005. 